\title{
From Traditional to New Media - Pmi (Public Media Institution Radio Television of Vojvodina) Rtv of Vojvodina in Step with the 21st Century and Media Literacy
}

\author{
MsC Sonja Kokotović \\ The coordinator in the cabinet General Director of the PMI RTV; \\ PhD student at the Faculty of Technical Sciences \\ PhD Miodrag Koprivica \\ General Director of the PMI RTV; \\ Professor at the Faculty of Law and Business Studies
}

\begin{abstract}
Today, digital media technologies enable faster reaching the necessary information and placement information that are important to the user, quickly and easily using new communication channels available to everyone around the world. Internet mainly compared with the "information buffet" from which users take as much information as he is when he needs to. This information can be used for information, education, entertainment, advertising, sales, and other aspects of the business. As we live in the age of new media, which enabled the creation and exchange a wide variety of content, including the content of traditional media such as those produced by JMU broadcasting a large number of Internet users, researchers influence of the media warn of increase dependence on the media, especially new and the need to create the institutional basis for the introduction of media education in the regular education program. Gradual influence of new media people indirectly determine the meaning of life, because it is believed that two-thirds of our waking time with the media or with media and other activity. This work will define terms such as Internet, communications, new media, media literacy, social media, media content, but ... I will analyze the expectations and challenges that we accelerated technical and technological developments made in terms of the Internet and other forms of electronic promotions.
\end{abstract}

Keywords: Internet, communications, new media, media literacy, social media, media content. 